\title{
INTERAKSI SOSIAL KKM 46 PADA KEGIATAN KHITAN MASSAL DI DESA BANJARSARI KECAMATAN WARUNG GUNUNG KABUPATEN LEBAK TAHUN 2017
}

\author{
Fatari $^{1}{ }^{1}$ Asnawi $^{2}$, Ahmad Munawir $^{3}$, Surachman $^{4}$, Gatot Hartoko $^{5}$, Ardi Hidayat ${ }^{6}$, Hadi \\ Kurniawanto ${ }^{7}$ \\ 1,2,3,4,5,6,7 Universitas Bina Bangsa Banten \\ E-mail: ${ }^{1}$ fatari.binabangsa@gmail.com, ${ }^{2}$ asnawi.binabangsa@gmail.com, \\ 3ahmad.munawir.binabangsa@gmail.com
}

\begin{abstract}
Abstrak
Khitan atau sunatan sudah sangat familier dan biasa kita dengar. Dibeberapa tempat, acara khitanan anak anak bahkan dijadikan acara hajatan. Namun kegiatan yang dilakukan oleh kelompok 46 merupakan kegiatan pengabdian berupa interaksi social masyarakat. Tujuan dari penulisan ini untuk penyampaian informasi tentang kegiatan Kuliah Kerja Mahasiswa (KKM) Kelompok 46 di desa Banjarsari kecamatan Warung Gunung kabupaten Lebak, dari beberapa program kegiatan, KKM Kelompok 46 melaksanakan program pokok yaitu kegiatan Khitan Massal yang meliputi (1) partisipasi masyarakat dalam kegiatan dan langkah evaluasi terhadap pelaksanaan program dan (2) capaian program kerja dan dampak kegiatan bagi masyarakat khususnya dampak manfaat bagi masyarakat desa Banjarsari. Dalam pelaksanaan Kuliah Kerja Mahasiswa (KKM) STIE Bina Bangsa tahun 2017 oleh kelompok 46 menggunakan metode Participatory Rural Appraisal (PRA) dan metode pendekatan social kemasyarakatan. Pelaksanaan kegiatan Khitan Massal ini, diikuti oleh 10 (sepuluh) anak dari keluarga yang kurang mampu perwakilan setiap RT, yang berada di desa Banjarsari, dan berjalan lancar dari awal sampai akhir pelaksanaannya.
\end{abstract}

Kata Kunci : Interaksi Sosial, Khitan Massal

\begin{abstract}
Circumcision or circumcision is very familiar and we usually hear. In some places, the child circumcision event even made a celebration event. But the activities carried out by group 46 are community service activities in the form of social interaction. The purpose of this paper is to deliver information about the Group 46 Student Work Lecture (KKM) activities in the village of Banjarsari, Warung Gunung sub-district, Lebak district, from a number of program activities, the Group 46 KKM carries out a main program namely Mass Circumcision activities which include (1) community participation in activities and evaluation steps towards the implementation of the program and (2) work program achievements and impacts of activities for the community especially the impact of benefits for the Banjarsari village community. In the implementation of the 2017 STIE Bina Bangsa Student Work Lecture (KKM) by group 46 using the Participatory Rural Appraisal (PRA) method and the social approach approach. The implementation of the Mass Circumcision activity was followed by 10 (ten) children from underprivileged families representing each $R T$, who were in the village of Banjarsari, and proceeded smoothly from the beginning to the end.
\end{abstract}

Keywords: Social Interaction, Mass Circumcision

\section{PENDAHULUAN}

Interaksi sosial merupakan hubungan hubungan soasial yang menyangkut hubungan antar individu individu (sesorang) dengan kelompok, dan kelompok dengan kelompok. Tanpa adanya interaksi social maka tidak akan mungkin ada kehidupan bersama. Proses social adalah suatu interaksi atau hubungan timbal balik atau saling mempengaruhi antar manusia yang berlangsung sepanjang hidupnya didalam masyarakat.

Homans (dalam Ali, 2004: 87) mendefinisikan bahwa interaksi sebagai suatu kejadian ketika suatu aktivitas yang dilakukan oleh seseorang terhadap individu 
laindiberi ganjaran atau hukuman dengan menggunakan suatu tindakan oleh individu lain yang menjadi pasangannya.

Konsep yang dikemukakan oleh Homans ini mengandung pengertian bahwa interaksi adalah suatu tindakan yang dilakukan oleh seseorang dalam interaksi merupakan suatu stimulus bagi tindakan individu yang lain yang menjadi pasangannya. Menurut Bonner (dalam Ali, 2004) interaksi merupakan suatu hubungan antara dua orang atau lebih individu, dimana kelakuan individu mempengaruhi, mengubah atau mempengaruhi individu lainatau sebaliknya.

Khitan atau sunatan sudah sangat familier dan biasa kita dengar. Dibeberapa tempat, acara khitanan anak anak bahkan dijadikan acara hajatan. Khitan adalah bentuk masdhar (kata dasar) dari khatana, yang artinya memotong. Al-Khitaan, Al-lkhtitaan adalah isim (kata benda) dari fi'il (kata kerja) al-khaatin, atau sebutan sebutan tempat yang dikhitan, yaitu kulit yang tersisa setelah dipotong. (Al-Isawi, 2008). Menurut istilah khitan pada laki laki adalah memotong kulit yang menutupi ujung kemaluan laki laki yang disebut Qulfah, agar tidak terhimpun kotoran didalamnya, dan juga dapat menuntaskan air kencing.

Desa merupakan satu wilayah yang di tempati sejumlah penduduk dan satu organisasi pemerintah terendah. Wilayah desa terdiri atas beberapa dusun atau kampung. Dusun atau kampung terdiri atas beberapa RW dan RT.

Desa menurut UU No. 32 Tahun 2004 adalah kesatuan masyarakat hukum yang memiliki luas wilayah yang berwenang untuk mengatur dan mengurus kepentingan masyarakat setempat, berdasarkan asal usul dan adat istiadat setempat yang diakui dan dihormati dalam sistem pemerintah Negara Kesatuan Republik Indonesia.

Desa Banjarsari merupakan penggabungan dari tiga desa yang mana sebelum tahun 1932, yaitu Desa Citundun, Desa Cileungsir dan Desa Mantare. Pada pertengahan tahun 1932 membentuk musyawarah membahas penggabungan desa penentuan nama desa. Dari hasil kesepakatan tersebut terbentuklah nama Desa Banjarsari yang mana arti dari nama Desa Banjarsari diambil dari dua kata yaitu Banjar yang artinya "tempat" dan kata Sari yang artinya "aneka ragam" jadi nama Banjarsari adalah tempat yang memiliki aneka ragam.

Sejak tahun 1932 nama desa menjadi Desa Banjarsari dan dipimpin oleh Kepala Desa (Jaro) dan dilakukan pemilihan kepala desa pertama pada tahun 1993 dengan kepala desa yang terpilih adalah bapak umar. Desa Banjarsari memiliki luas wilayah 533,00 Ha. Dengan ketinggian 190 Meter di atas permukaan laut. Berdasarkan data administrasi Pemerintah Desa, masyarakat di Desa Banjarsari mayoritas beragama Islam dengan jumlah penduduk yang tercatat secara administrasi, jumlah total 5.676 Jiwa. Dengan rincian penduduk berjenis kelamin laki-laki 2.942 jiwa, sedangkan berjenis kelamin perempuan berjumlah 2.734 jiwa. Secara umum mata pencaharian warga Desa Banjarsari dapat teridentifikasi kedalam beberapa bidang mata pencaharian, seperti : Petani, Buruh tani, PNS, karyawan Swasta, pedagang, wirausaha, pensiunan, tukang dan peternakan.

Tujuan dari penulisan ini untuk penyampaian informasi tentang kegiatan Kuliah Kerja Mahasiswa (KKM) Kelompok 46 di desa Banjarsari kecamatan Warung Gunung kabupaten Lebak, dari beberapa program kegiatan, KKM Kelompok 46 melaksanakan program pokok yaitu kegiatan Khitan Massal yang meliputi (1) partisipasi masyarakat dalam kegiatan dan langkah evaluasi terhadap pelaksanaan program dan (2) capaian program kerja dan dampak kegiatan bagi masyarakat khususnya dampak manfaat bagi masyarakat desa Banjarsari. 


\section{METODE PELAKSANAAN}

\subsection{Tahapan Pelaksanaan}

Tahapan pelaksanaan untuk kegiatan Khitan Massal KKM Kelompok 46 dibuat dalam bentuk bagan, seperti ditunjukan pada gambar 1 .

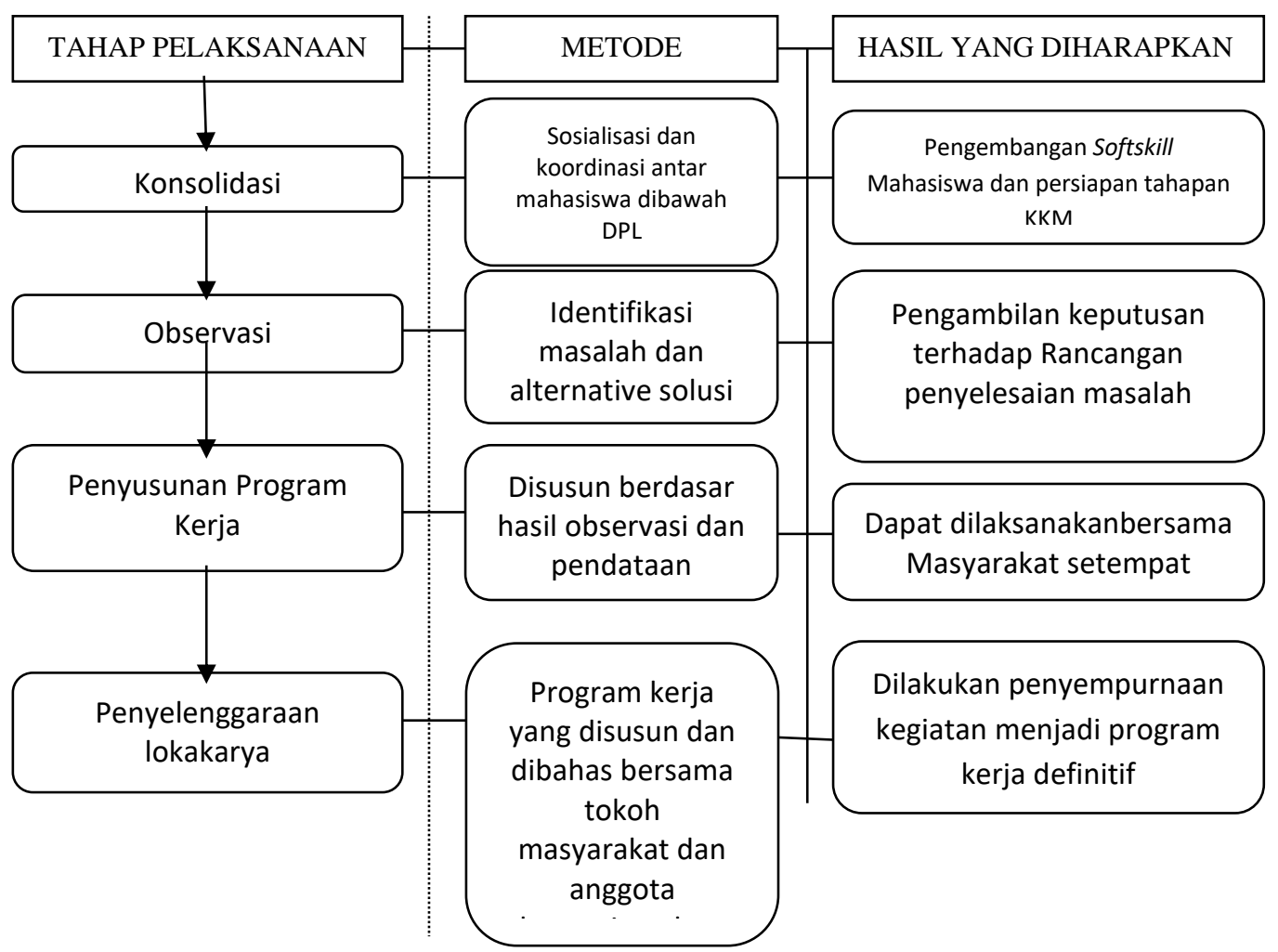

Gambar 1. Bagan tahapan pelaksanaan kegiatan

Berdasarkan bagan tahapan pelaksanaan kegiatan, KKM Kelompok 46 tahun 2017 di desa Banajarsari, maka jadwal kegiatan dapat dilihat pada table berikut :

Tabel 1. Jadwal kegiatan Kelompok 46

\begin{tabular}{|c|l|c|c|c|c}
\hline \multirow{2}{*}{ No. } & \multicolumn{1}{c|}{ PROGRAM KEGIATAN } & \multicolumn{4}{c}{ Pekan ke } \\
\cline { 4 - 6 } & \multicolumn{1}{c}{ Bidang Sosial dan Budaya (Khitan Massal) } & & & & \\
\hline 1. & Identifikasi Masalah & & & & \\
\hline 2. & Perencanaan Kegiatan dan survei lapangan & & & & \\
\hline 3. & Koordinasi Dinas terkait (Dinas Kesehatan) & & & & \\
\hline 4. & Pelaksanaan Kegiatan & & & & \\
\hline 5. & Laporan dan Evaluasi & & & & \\
\hline
\end{tabular}




\section{$6 . \quad$ Lokakarya}

\subsection{Alasan Pemilihan Program Kegiatan}

Pemilihan terhadap program utama yaitu kegiatan Khitan Massal, untuk kegiatan didasari oleh situasi dan kondisi yang ditemui saat survey awal dan pelaksanaan Kuliah Kerja Mahasiswa (KKM) oleh kelompok 46. Pemilihan program Khitan Massal dilakukan untuk membantu warga yang kurang mampu, setelah diidentifikasi ternyata banyak anak anak di desa Banjarsari terutama anak laki laki yang sudah memasuki usia sekolah tapi belum dikhitan. Hasil wawancara dengan beberapa orang tua yang menyatakan bahwa mereka berkeinginan mengkhitan anak anak mereka, namun belum ada biaya atau keterbatasan biaya, sehingga kami KKM Kelompok 46 berinisiatif untuk melakukan kegiatan Khitan Massal. Dan program tersebut kami jadikan sebagai program utama atau program unggulan.

Program Khitan Massal kami anggap penting, karena itu merupakan bentuk program pengadian pada masyarakat yang dapat kami lakukan, yang dampaknya sangat besar dirasakan oleh masyarakat, sehingga masyarakat khususnya masyarakat desa Banjasari menyambut baik bahkan sangat antusias terhadap program yang kami tawarkan. Bagi kami KKM Kelompok 46, kegiatan Khitan Massal merupakan kegiatan yang bukan saja seremonial saja akan tetapi merupakan kegiatan yang bersifat monumental.

\subsection{Metode Pendekatan}

Dalam pelaksanaan Kuliah Kerja Mahasiswa (KKM) STIE Bina Bangsa tahun 2017 oleh kelompok 46 menggunakan metode Participatory Rural Appraisal (PRA) dan metode pendekatan social kemasyarakatan.

\section{Metode Participatory Rural Appraisal (PRA)}

Metode dengan melibatkan masyarakat mulai dari tahap perencanaan, pelaksanaan, pemanfaatan dan evaluasi. Dalam metode $P R A$, memungkinkan masyarakat desa saling berbagi dan menganalisis pengetahuan tentang kondisi lingkungannya dalam rangka pembuatan perencanaan dan tindakan. Metode PRA merupakan cara yang digunakan dalam pelaksanaan kajian untuk memahami keadaan atau situasi dan kondisi desa dengan melibatkan atau partisipasi masyarakat, atau pengkajian atau penilaian terhadap desa secara partisipasif.

Penggunaan metode PRA bertujuan untuk menghasilkan rancangan program yang relevan dengan keadaan masyarakat, agar masyarakat mampu dalam menganalisis keadaan diri dan diwujudkan dengan perencanaan, pelaksanaan dan realisasi dapat berkembang, sehingga dapat dibuat program dan pelaksanaannya. Dalam kegiatan PRA ini, mahasiswa hanya sebagai fasilitator sekaligus mativator dan masyarakatlah sebagai pelaksananya.

\section{Pendekatan Sosial}

Dalam pelaksanaan program kegiatan ini, KKM kelompok 46 juga menggunakan pendekatan social, baik pada tahap perencanaan, pelaksanaan maupun pada tahap evaluasi. Dalam tahap perencanaan, pendekatan social dilakukan dengan melibatkan masyarakat secara langsung maupun tidak langsung, dalam penyusunan program kegiatan yang dilakukan oleh KKM Kelompok 46. Melibatkan (partisipasi) masyarakat dalam perencanaan, dapat teridentifikasi berbagai harapan (ekspektasi), kebutuhan dan permasalahan nyata yang dihadapi masyarakat, sehingga dapat disusun perencanaan yang matang, lebih tepat dan realistis. Semakin banyak masyarakat yang dilibatkan 
tentunya semakin baik. Disamping itu, keterlibatan masyarakat dalam perencanaan dapat membawa efek psikologis untuk bersama sama bertanggung jawab dala implementasi terhadap rencana yang sudah dibuat.

Pendekatan dalam tahap pelaksanaan, terutama dilakukan oleh mahasiswa KKM Kelompok 46 melalui penciptaan komunikasi dan hubungan social yang harmonis untuk bersama sama melaksanakan setiap rencana yang sudah disusun. Dibandingkan dengan tahapan lainnya. Pendekatan social memegang peranan penting dan harus banyak dilakukan oleh para mahasiswa khususnya KKM Kelompok 46. Pendekatan social dalam tahap evaluasi berhubungan erat dengan partisipasi masyarakat untuk memberikan data secara obyektif atas kegagalan dan keberhasilan kegiatan Kuliah Kerja Mahasiswa (KKM) Kelompok 46.

\section{HASIL DAN PEMBAHASAN}

Partisipasi masyarakat dalam kegiatan ini, meliputi: 1) Penyiapan situasi dan kondisi terhadap masyarakat yang bersedia ikut serta dalam program kegiatan Khitan Massal; 2) Kerja sama dalam perencanaan, pelaksanaan, pemanfaatan, dan evaluasi; 3) Menyiapkan tempat kegiatan pelaksanaan Khitan massal; dan 4) Masyarakat bekerja bersama untuk realisasikan program yang telah dibuat.

Evaluasi yang telah dilakukan terdiri atas evaluasi terhadap proses dan hasil. Evaluasi proses, terkait dengan perencanaan, dan proses pelaksanaan. Evaluasi proses dilakukan setiap pekan bersama tokoh masyarakat dan tokoh pemuda yang terdapat di Desa Banjarsari. Evaluasi hasil, dilaksanakan setelah kegiatan selesai setiap hari saat malam bertempat di Posko. Evaluasi hasil ditujukan untuk mengetahui sejauh mana program KKM Kelompok 46 dapat terlaksana.

\subsection{Kegiatan Khitan Massal}

Pelaksanaan program utama pada pelaksanaan Kuliah Kerja Mahasiswa dari STIE Bina Bangsa Banten tahun 2017 yang dilaksanakan oleh Kelompok 46 di desa Banjarsari Kecamatan Warung Gunung Kabupaten Lebak Provinsi Banten, yaitu Program kegiatan berupa Khitan Massal, yang dilaksanakann pada tanggal 20 Agustus tahun 2017, bertempat dikantor desa Banjarsari Kecamatan Warung Gunung Lebak.

Pada kegiatan Khitan Massal ini, panitia pelaksana yaitu Mahasiswa KKM Kelompok 46 didampingi oleh Dosen Pembimbing Lapangan (DPL), mendatangkan ahli khitan dari RSUD Kota Cilegon yaitu bapak Ahmad Hadi dan bapak Ma'mun. Pada kegiatan tersebut dihadiri oleh bapak kepala desa Banjarsari,dan para orang tua yang anaknya akan di Khitan, bapak Babinsa kecamatan Warung Gunung, para sesepuh serta tokoh masyarakat desa Banjarsari.

Pelaksanaan kegiatan Khitan Massal ini, diikuti oleh 10 (sepuluh) anak dari keluarga yang kurang mampu perwakilan setiap RT, yang berada di desa Banjarsari, dan berjalan lancar dari awal sampai akhir pelaksanaannya.

\subsection{Dokumentasi Kegiatan Khitan Massal}




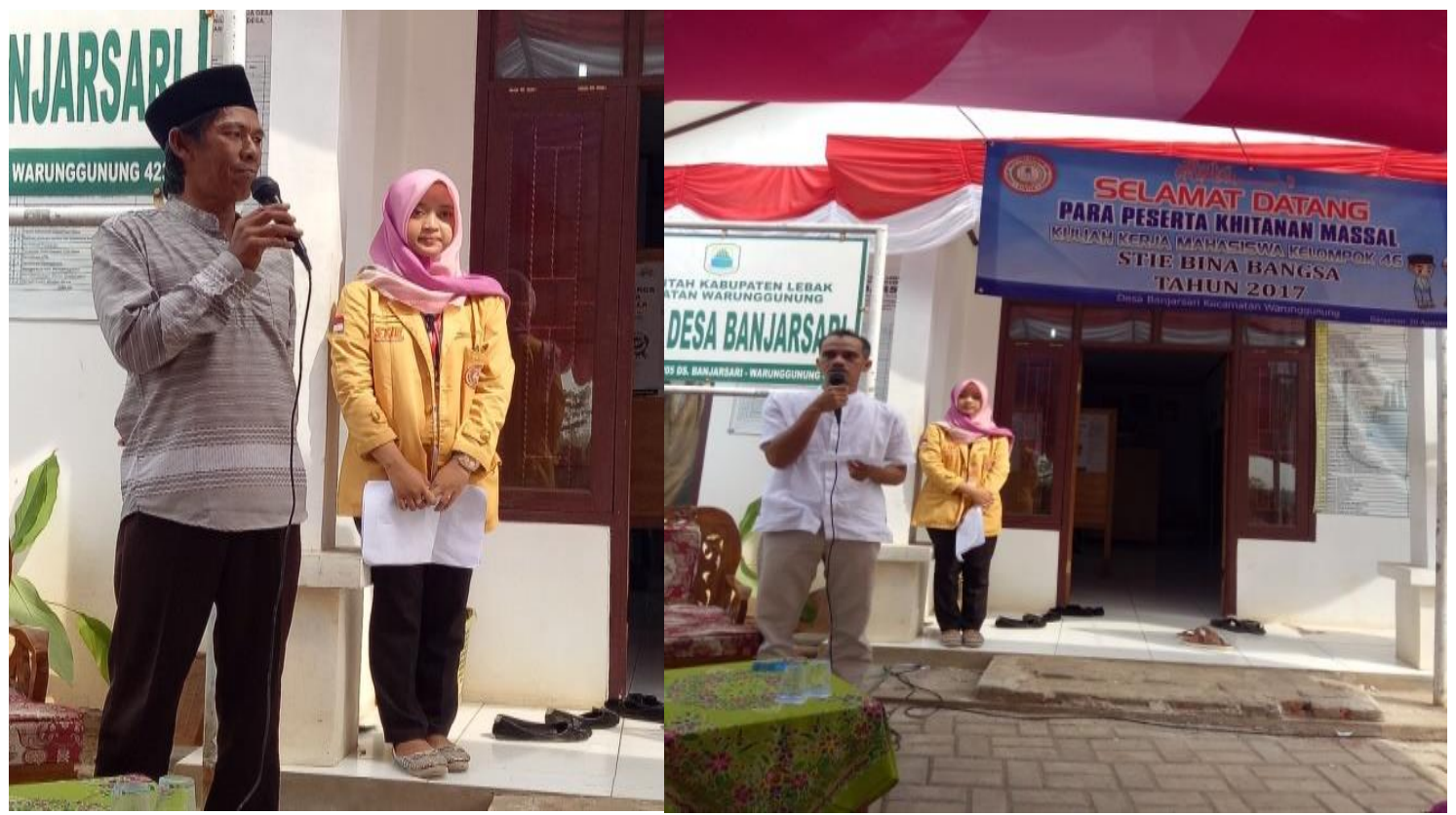

Gambar 1. Sambutan Kepala Desa dan tim dokter

Sambutan Kepala desa Banjarsari dalam rangka pembukaan kegiatan Khitan Masal yang dilakukan oleh mahasiswa KKM Kelompok 46. Dalam sambutannya bapak kepala menyampaikan apresiasi dan ucapan terimakasih kepada mahasiswa yang sudah melakukan kegiatan khitan masal ini, sekaligus memberikan pemahaman kepada masyarakat sekitar tentang betapa pentingnya khitan masal tersebut diantaranya adalah dapat membantu warga yang kurang mampu.

Dilanjutkan dengan sambutan dari tim dokter yang memberikan pesan sekaligus memberikan motivasi kepada para peserta khitan masal agar tidak trauma, karena tidak sedikit banyak anak anak yang merasa takut bahkan tidak mau untuk dikhitan, oleh karena itu pemberian pemahaman ini sangat penting dilakukan.

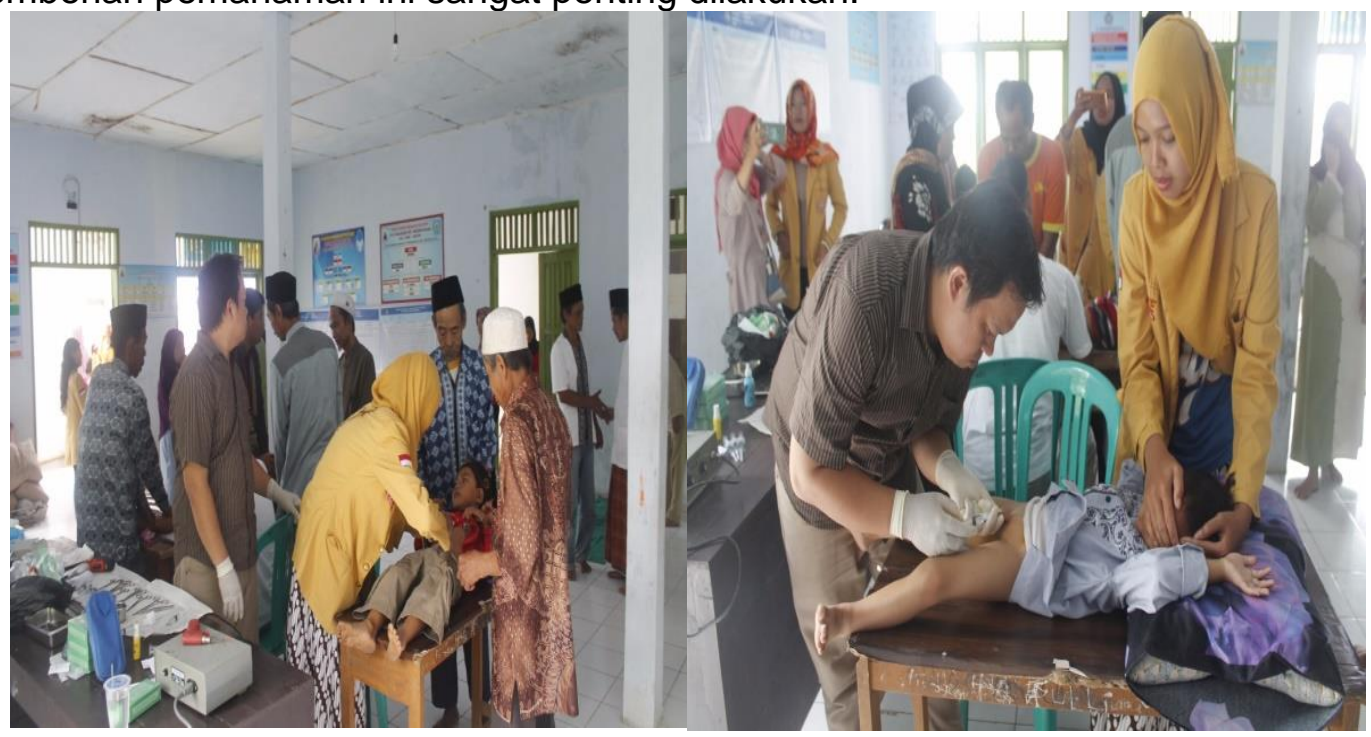

Gambar 2. Pelaksanaan kegiatan Khitan Massal 


\subsection{Lokakarya}

Kegiatan Lokakarya yang dilakukan oleh KKM Kelompok 46 di desa Banjarsari kecamatan Warung Gunung dibagi kedalam beberapa tahapan antara lain : 1) Lokakarya ditingkat Kecamatan dilaksanakan pada tanggal 28 Agustus 2019 dan dihadiri oleh beberapa unsur kecamatan termasuk bapak camat Warung Gunung. Kegiatan ini dilakukan bertujuan untuk memberitahukan sekaligus melaporkan hasil kegiatan KKM Kelompok 46 selama berlangsung bahwa pelaksanaan tersebut telah selesai; 2) Lokakarya tingkat desa dilaksanakan pada tanggal 29 Agustus 2019, dihadiri oleh kepala desa dan jajarannya dan hadiri pula oleh tokoh masyarakat desa setempat. Kegiatan ini dilaksanakan untuk memberitahu dan melaporkan hasil kegiatan KKM Kelompok 46 di desa Banjarsari telah selesai dilaksanakan, sekaligus pamit dan perpisahan kepada seluruh jajaran pemerintahan desa dan warga setempat; 3) Lokakarya tingkat Kampus dilaksanakan pada tanggal 08 dan 16 September 2019 di kampus Bina Bangsa. Dari hasil lokakarya tingkat kampus, KKM Kelompok 46 mendapatkan juara 3 dan mendapatkan hadiah berupa pembinaan.

\subsection{Dokumentasi Kegiatan Lokakarya}

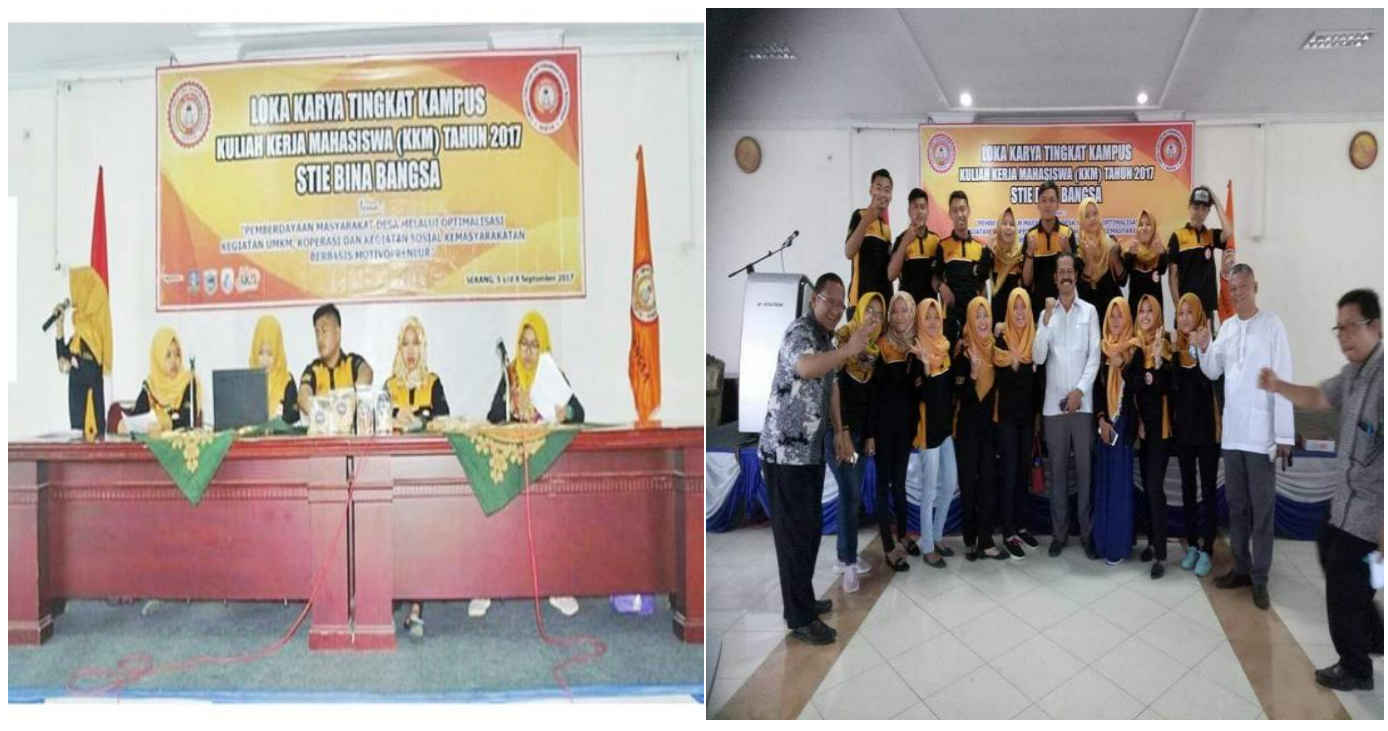

Gambar 3. Kegiatan Lokakarya
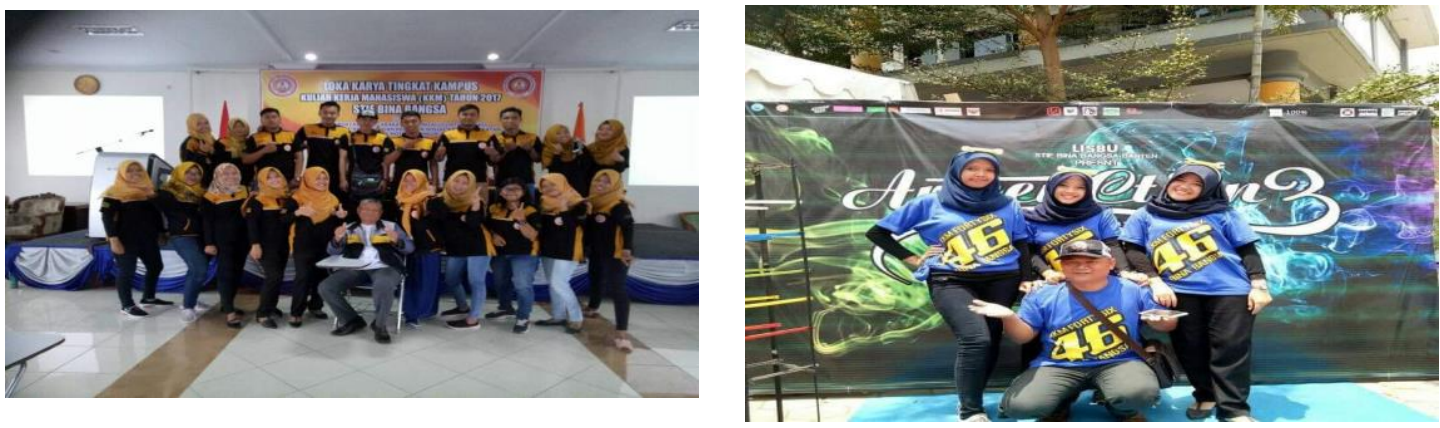


\section{Gambar 4. Lokakarya tingkat Kampus sebagai juara 3}

\section{KESIMPULAN}

Interkasi sosial oleh mahasiswa KKM Kelompok 46 di desa Banjarsari kecamatan Warung Gunung yang terfokus pada program kegiatan social kemasyarakatan yakni Khitan Massal, merupakan upaya pemberdayaan terhadap masyarakat sasaran. Hal itu ditunjukkan dengan partsipasi masyarakat dalam bentuk penyiapan situasi dan kondisi, kerja sama, penyiapan tempat, dan masyarakat bekerja bersama. Di sisi lain, evaluasi juga telah dilakukan terdiri atas evaluasi terhadap proses dilakukan setiap pekan bersama tokoh-tokoh masyarakat dan para pemuda yang terdapat di Desa Banjarsari, sedangkan evaluasi terhadap hasil dilaksanakan setelah kegiatan selesai dilaksanakan. Evaluasi hasil ditujukan untuk mengetahui sejauh mana program KKM Kelompok 46 terlaksana.

Capaian program kerja utama yaitu kegiatan Khitan Massal dapat terlaksana 100\% tidak ada kendala yang berarti, dan hasilnya dapat bermanfaat untuk masyarakat sekitar khususnya masyarakat desa Banjarsari yang kurang mampu. Capaian ini berdampak langsung pada masyarakat, sehingga masyarakat antusias menyambut kegiatan ini, karena ini merupakan sebuah momentum bersejarah, bukan saja kegiatan yang bersifat seremonial, akan tetapi merupakan kegiatan yang sifatnya monumental.

Dari upaya dan capaian yang sudah dilakukan oleh KKM Kelompok 46 di desa Banjarsari kecamatan Warung gunung, maka diperlukan kegiatan serupa secara berkesinambungan dimasa yang akan datang, oleh karena itu kami memberikan rekomendasi antara lain :

1) Adanya upaya untuk meningkatkan hasil ekonomi bagi warga masyarakat desa yang kurang mampu, dengan demikian warga masyarakat dapat menghitan anak anaknya secara mandiri.

2) Perlu adanya penyuluhan kesehatan dari dinas terkait bahwa pentingnya menghitan anak anak sebelum mereka beranjak dewasa.

3) Perlu adanya kerjasama khususnya pemerintahan desa Banjarsari kecamatan Warung Gunung dengan lembaga lembaga yang biasa menyelenggarakan kegiatan Khitan Massal.

4) Perlu adanya kegiatan serupa, mengingat kegiatan Khitan Massal ini sangat membantu dan sangat bermanfaat bagi masyarakat.

\section{DAFTAR PUSTAKA}

Hikmat, R. H, 2001. Strategi Pemberdayaan Masyarakat, Cetakan ke-1. Bandung: Humaniora Utama Press (HUP).

Homans, dalam Ali, 2004, Pengertian Interaksi Sosial, www.belajarpsikologi.com

Jogloabang.com. (n.d.). UU 6 tahun 2014 tentang Desa. https://www.jogloabang.com 
Manarul Ahmad. (2016). Pengertian Interaksi Sosial Menurut Para Ahli. In Yuksinau.com (p. 1). http://www.yuksinau.com/2016/04/pengertian-interaksi-sosial-menurut-para$\underline{\text { ahli.html }}$

Sriyono, S., Sari, D. K., Febriansah, R. E., \& Prapanca, D. (2019). Pendampingan Tata Kelola Dan Manajemen Pada Kegiatan Abdimas Masjid. In Jurnal Terapan Abdimas (Vol. 4, Issue 2). https://doi.org/10.25273/jta.v4i2.4846

STIE Bina Bangsa, 2017, Panduan Kuliah Kerja Mahasiswa dan Penulisan Laporan KKM Tahun 2017, Serang, LPPM

Subakti, H., Eka Selvi Handayani, Anisa Anindi Muslimah, Sella Shinta, \& Dodi Alfayed. (2020). PENGENALAN MODEL MIND MAPPING DALAM PEMBELAJARAN MENULIS CERITA PENDEK DI SD NEGERI 002 SUNGAI PINANG KOTA SAMARINDA. Jurnal Abdimas Bina Bangsa, 1(1), 71-79. doi:10.46306/jabb.v1i1.6

Susetiawan, S., Mulyono, D., \& Roniardian, M. Y. (2018). Penguatan Peran Warga Masyarakat Dalam Perencanaan, Penganggaran, dan Evaluasi Hasil Pembangunan Desa. In Jurnal Pengabdian Kepada Masyarakat (Vol. 4, Issue 1). https://doi.org/10.22146/jpkm.27512

Undang Undang No. 32 Tahun 2004, Tentang Pemerintahan Desa

Yuliah, Raden Irna Afriani, \& Ina Khodijah. (2020). PEMBERDAYAAN PEREMPUAN DAN DIVERSIFIKASI OLAHAN IKAN BANDENG DI DESA SAWAH LUHUR. Jurnal Abdimas Bina Bangsa, 1(2), 153-161. doi:10.46306/jabb.v1i2.15 